DOI 10.37882/2500-3682.2020.06.09

\title{
ПСИХОТЕРАПЕВТИЧЕСКОЕ КОНСУЛЬТИРОВАНИЕ КЛИЕНТОВ, ПОДВЕРЖЕННЫХ ЗАВИСИМОСТИ ОТ ВИРТУАЛЬНОГО СЕКСА
}

\section{PSYCHOTHERAPY COUNSELING FOR CLIENTS WHO ARE ADDICTED TO VIRTUAL SEX}

\section{Makarova}

Summary: The article identifies the main directions of sexual behavior in modern society, which is necessary to present to a specialist in psychotherapeutic counseling. The analysis of prerequisites, types and features of virtual sex is carried out. The description of a potential Client and a typology of virtual sex adherents, as well as a description of psychotherapeutic directions suitable for the request for dependence on virtual sex are made.

Keywords: virtual sex, virtual sex addiction, sexual behavior, virtual relationships, psychosexual disorders.

\author{
Макарова Мария Владимировна \\ психолог-консультант, Телефон Доверия Кризисного \\ центра «812», Санкт-Петербург \\ maria.makarova.mow@gmail.com
}

Аннотация: В статье обозначаются основные направления сексуального поведения в современном обществе, необходимого для представления специалисту по психотерапевтическому консультированию. Проведён анализ предпосылок, видов и особенностей виртуального секса. Составлено описание потенциального Клиента и типология приверженцев виртуального секса, а также описание психотерапевтических направлений, подходящих под запрос о зависимости от виртуального секса.

Ключевые слова: слова: виртуальный секс, зависимость от вирта, сексуальное поведение, виртуальные отношения, психосексуальные расстройства.

3. описание психотерапевтических направлений, подходящих под запрос о зависимости от виртуального секса;

В работе использовались исследования и материалы российских и западных психотерапевтов, сексологов, специалистов в указанной теме. Также для подготовки рабочего материала и осмысления теоретических знаний была проведена супервизорская встреча с известным российским сексологом, сексопатологом, психотерапевтом, к.м.н. Ю.П. Прокопенко.

\section{Особенности сексуального поведения. Виртуальный секс}

на приём к психологу попадают люди, имеющие новые формы зависимости, так или иначе, связанные с темой секса, например, зависимость от виртуального секса.

Таким образом, целью статьи является подготовка и моделирование приёма Клиента, запрос которого касается проблематики зависимости от виртуального секса.

Основными задачами работы видятся следующие направления:

1. обозначение основных направлений сексуального поведения в современном обществе, необходимого для представления специалисту по психотерапевтическому консультированию; анализ предпосылок, видов и особенностей виртуального секса;

2. описание потенциального Клиента и типология приверженцев виртуального секса;
В первую очередь необходимо отметить, что сексуальное поведение исключительно индивидуально: от пансексуализма до полного отказа от секса. Как пишет профессор Кащенко Е.А., «истина, как всегда, посередине - в социокультурном подходе, в гармоничном единении между «верхом» и «низом», душой и плотью. А этот подход предполагает формирование сексуального (и не только) поведения посредством всего многообразия мер, средств, форм и способов, которые выработало человечество в ходе исторического развития.»[11]. Таким образом, жизнь без секса так же нормальна, как и жизнь с сексом. Разумеется, каждый индивид разрешает одну или несколько психосексуальных задач, которые отвечают его собственным целям (тем не менее, стоит перечислить все цели сексуальной активности человека: релаксация, прокреация, рекреация, познание, комму- 
никация, самоутверждение, достижение внесексуального самоутверждения (получение статуса, брак по расчету), проведение ритуала, компенсация недостающих форм деятельности, созидание (искусство, культура).). Здесь также необходимо упомянуть о том, что каждому возрастному периоду необходим свой определенный секс[11]. При этом есть существенная разница в телесном, психологическом и социальном восприятии половой жизни у мужчин и женщин. В этой связи, напрашивается вывод о том, что тема регулярности половой жизни партнеров весьма дискуссионна и не подлежит среднестатистическому оцениванию. Здесь и далее мы будем отталкиваться именно от этой позиции - индивидуальных предпочтений, субъективных переживаний и ожиданий клиентов.

Тем не менее, рассуждая о формах полового удовлетворения, нельзя не сказать о людях с иной манерой сексуального поведения - сексуальных девиациях (Они могут получить сексуальное удовлетворение только совершенно определенными способами, которые основаны, например, на визуальном восприятии: эксгибиционизм, вуайеризм, нарциссизм, пигмалионизм.). Если речь идёт о реально девиантном поведении, которое подлежит уголовной ответственности, то подход к таким пациентам иной (что лежит за рамками исследования). И подобные девиации не всегда имеют патологический характер: чаще встречаются какие-то отдельные проявления или их совокупность, которые не вредят. Когда встает вопрос что есть норма, а что болезнь, психотерапевты отталкиваются от переживаний конкретного человека, который испытывает палитру негативных эмоций из-за отсутствия секса, или от такого параметра как дисгармония непосредственно в паре. Наравне с психологической, нельзя полностью отметать физиологическую составляющую сексуальной жизни. Существуют удивительные кейсы, когда половое влечение снижается только с конкретным партнером (селективные расстройства), или, допустим, на сессии выясняется, что для конкретной женщины оргазм, как таковой, не представляет интереса - ей приятен и важен сам процесс [5].

Желание реализовать свой сексуальный потенциал (при гиперэротизме (гиперэротизм - аномально повышенное половое влечение у женщин (нимфомания) и мужчин (сатириаз)) любыми доступными формами полового общения, особенно в условиях сегодняшней технической возможности, рано или поздно могут привести любого человека к виртуальному сексу. Также некоторые используют новые экзотические способы, чтобы вылечить свою фригидность (у женщин), или с целью нащупать новые экстремальные сексуальные стимулы для затухающего полового влечения (мужчины). Здесь и далее с точки зрения классификации полового влечения мы будем говорить об экстрагенитальной форме [2].
В соответствии с общепринятым представлением «Виртуа́льный секс (также вирт) - процесс, во время которого два или более человека взаимодействуют в виртуальном пространстве, при помощи какого-либо коммуникационного оборудования (телефон, программа мгновенного обмена текстовыми сообщениями, видеосвязь), с целью сексуального удовлетворения друг друга при помощи отправления соответствующих стимулирующих сообщений, как текстовых, так и мультимедиа. Для частных разновидностей существуют свои названия: секс по телефону, киберсекс, эротический видеочат и пр.» [3]. Для уточнения специфической терминологии необходимо выделить «Сетевой секс», как экстрагенитальный род некой суррогатной половой активности, синоним «вирта», и предполагающий наличие компьютерных технологий и Интернета.

Для виртуального (суррогатного) мира интимных отношений следует выделить некоторые особенности. Например, «секс по телефону», который практически полностью изжил себя, передал свои особенности общения сетевому сексу: вульгарная и стилистически сниженная лексика виртуального общения, а также желание мужчин сначала пожаловаться на жизнь, познакомиться ближе и перевести всё в реальную плоскость. Особенностью веб-пространства является возможность описательного характера секса онлайн между реально существующими партнерами. Времени между написание сообщения, его прочтением и ответом хватает на возбуждение. Со стороны такая переписка покажется недостаточно интересной, но в процессе партнеры получаются всё, что нужно: возможность представлять и фантазировать, позволять себе то, что невозможно представить в реальной жизни. Помимо этого, это безопасно, доступно, экономично, анонимно, есть возможность самостоятельного выбора или отказа от чего-то неподходящего. Здесь создаются роли: обычная домохозяйка представляется сексбомбой, мужчина может стать женщиной, женатый - холостяком. Это невероятное поле для удовлетворения любых впечатляющих фантазий.

Статистика этому подтверждение: огромное количество кликов по ключевым запросам: вирт, секс, знакомства, флирт и т.д. Огромное количество сайтов, форумов, чатов по пристрастиям: игры, соблазнения, развратные девчонки, некто.ми, мэйл.ру и многие другие. Контекстная всплывающая реклама - предложений на рынке очень много.

От увлечения виртуальным сексом появляется масса негативных последствий: усугубление собственных комплексов личностного общения, формирование и поощрение сексуальной пассивности, деградация или зависимость от определенных сексуальных стимулов и эротических раздражителей [6]. К этому стоит добавить самую важную проблему пристрастия - со временем интерес к реальному сексу и к реальному партнеру утрачи- 
вается. Отсюда и начинаются межличностные и другие проблемы, с которыми потом обращаются за психотерапевтической помощью. В особо сложных случаях виртуальный секс может настолько сильно деформировать и разрушить психику, что человек в конечном итоге теряет всякую способность к сексуальной жизни и сосредоточен только на мире своих фантазий. Мастурбация, как результат занятий виртуальным сексом, в процессе самого ритуала (специфическая поза перед экраном с мышью и клавиатурой) приобретает иной смысл. Это суррогатное половое удовлетворение становится единственным способом вообще удовлетворить себя. Недостаточность эмоций (шизодный тип), отстраненность, страх ожидания, сомнения приводят к психосексуальным отклонениям. В случаях навязчивого желания заниматься мастурбацией в этих условиях, затуханием половой активности, ощущением всепоглощаемой потребности, страха невозможности самостоятельно преодолеть недуг - требуется психотерапевтическая консультация.

\section{Описание к^иента}

Эксперты и специалисты по-разному оценивают количество пристрастившихся к виртуальному сексу Интернет-пользователей. По некоторым оценкам, порядка трети активных пользователей практикуют виртуальный секс постоянно (данные на основе супервизорской консультации). Безусловно уже сейчас можно отметить наличие разных категорий пристрастившихся пользователей: есть те, кто занимаются исключительно сетевым сексом, а есть те, кто активно назначают свидания и желают увидеться в реальной жизни. Существует и виртуальная проституция. Потребностей много, как и самих активных пользователей. Нельзя точно определить соотношение мужчин и женщин, но существует гипотеза, что пристрастившихся мужчин больше, чем женщин. По мнению большинства женщин, виртуальным сексом больше склонны заниматься мужчины, поскольку это очень удобно для ленивых, инфантильных и неуверенных в себе (данные на основе супервизорской консультации). У мужчины среднего возраста, который чаще всего подвержен зависимости от виртуального секса, возникает ощущение, что он находится в «замкнутом круге», пагубная привычка овладевает им. Примерно у $50 \%$ любителей виртуального секса есть опасность попасть в зависимость от него [8].

Клиент может по-разному проецировать себя в сети: если вирт - это средство связи (мессенджер, почта, телефон, сообщения), то его поведение незначительно отличается от реального в жизни. Если же Клиент активно преображается: играет, флиртует, преследует иные цели, то его манеры могут быть весьма полярными. Интернетпространство даёт множество способов проявить себя: быть романтичным, пошлым, развратным, свободным. От этих «выпуклых» проявлений зависит тип участника этого процесса. Но проблему необходимо рассматривать ещё шире - в основе злоупотребления виртуальным сексом лежат отклонения в психике: зависимость от нетипичных стимулов сексуального возбуждения, и, как следствие, сексопатологические расстройства. Если один Клиент стремится решить свои конкретные задачи через виртуальный секс, то другой Клиент может усугубить уже имеющиеся. Например, при злоупотреблении появляется пренебрежительное отношение к романтическим отношениям, развитие парафилий и фобий [5]. Все эти проявления требуют оценки профильных специалистов.

По степени пристрастия к виртуальному сексу можно выделить четыре основные группы виртуалов [6]. Первая, это «Любопытные». (1) Склонные к новизне - у них есть тяга к исследованию, моде, экзотике, способ разнообразия своей сексуальной жизни. Но они быстро остывают, потому что не удовлетворяется главная потребность - реальная любовь. (2) Любители эротических фантазий - желание испытывать гамму разных эмоций и фантазий; нередко переносят опыт с вирта в реальность и тем самым усиливают свои сексуальные переживания. Также это способ пережить навязчивую сексуальную фантазию, не быть невротизированным. (3) Склонные к познанию - поиск новых знаний, способов, опыта. Осведомленность для них - это способ повысить собственный уровень сексуальной культуры

Вторая группа - «Озадаченные». Для этой категории вирт - это способ приспособиться к жизненным трудностям: например, физическое отсутствие возможности секса. Или узкий круг друзей и знакомых, где возникает чувство одиночества. Также сюда относятся люди с семейными проблемами, разрывами в коммуникации. Эта группа уже задается вопросом: а не слишком ли я часто сижу в Интернете? Не пристрастился ли? Если они начинают посвящать виртуальному сексу больше 12 часов в неделю, то они переходят в следующую категорию.

Третья группа «Зависимые» - это уже прямая зависимость от новых сексуальных стимулов. Желание постоянно сидеть в чатах настолько сильное, что приводит к раздражительности, неряшливости, невнимательности к окружающим. Их ведет импульсивное желание заниматься виртом в ущерб другим важным делам. Возникает чувство вины с низкой самооценкой после акта виртуального секса. В этой группе уже нет реального секса, есть уже конкретные сексуальные отклонения с разной этиологией: половая дисфункция, депрессия, тревожность и др.

Последняя группа «Озабоченные» представляют собой болезненное пристрастие к виртуальному сексу (парафилии), где вирт становится единственным источником удовлетворения их нетипичного влечения. Можно говорить о виртуальной мании «виртуафилии», они уже 
не готовы к живому общению вообще. Здесь требуется медикаментозное лечение (психотропные препараты) в сопровождении психотерапии, при полном запрете пользоваться Интернетом и компьютером. В этой группе выделяются: (1) Контакт с определенным партнером (зоофилы, педофилы, насильники, пр.), (2) Исключающие телесный контакт с другим человеком (копрофилы, фетишисты, садисты, мазохисты и пр.), (3) Удовлетворение от видеообраза (вуайеристы, кандаулезисты, нарциссисты (как разновидность сексуального фетишизма), скоптофилы, эксгибиционисты и пр.), (4) Удовлетворение от аудиоинформации (нарратофилы, уролалисты, эксаудиристы и др.).

Безусловно многие заболевания существовали и до появления злополучного Интернета и виртуального секса. Но сейчас у этого огромного количества потенциальных пациентов есть специальное место, где они могут виртуально встречаться, общаться, смотреть, играть. На таком широком активном диапазоне мы говорим о шведских парах, триолизме, групповом сексе, манилизме (одновременный контакт множества людей). Для таких людей виртуальный секс - это отдушина. Они выходят в свой мир, понимая социальную неприемлемость своего поведения. Они чувствуют вину и стыд за свои импульсивные сексуальные желания, и, конечно, имеют неудовлетворенные отношения со своими реальными постоянными партнерами.

Тем не менее, приверженность виртуальному сексу наносит большой ущерб общей культуре сексуального общения, как, например, неконтролируемое распространение порнографии [5]. Актуальная проблема - это половое просвещение подростков, которые не всегда могут правильно отличить плохое от хорошего. Третьей проблемой можно назвать усиливающий эффект уже имеющихся психосексуальных расстройств у отдельных категорий пользователей. Также немаловажно - это возникающие депрессии на фоне разочарования реальными сексуальными контактами после созданной иллюзии в рамках виртуального секса.

\section{Направления психотерапевтического консультирования}

Различия в подходах к терапии является естественным продолжением различия в философском обосновании разных медицинских, психологических и социологических школ. Подходы у врачей-сексологов и секс-терапевтов отличаются по клиническому мышлению и поиску заболевания, с одной стороны, и симптоматическому лечению с другой. В этой связи, необходимо отметить важность комплексного подхода к терапии - нельзя игнорировать психологические аспекты личности пациента или клиента, а также взаимоотношения партнеров в целом.
В основе любого подхода лежит всесторонняя оценка как самого Клиента, так и его партнера, а также их межличностных отношений. Ценность диагностики и лечения подкрепляется тщательным сбором информации. Терапия зависимости от виртуального секса может уложиться в краткосрочный курс (от 6 до 15 недель) и должна преследовать совершенно конкретные цели, связанные именно с интимной стороной отношений пары. Таким образом, цели подобной терапии можно установить на двух уровнях:

1. изменение сексуального поведения для более свободного проявления личных запросов в области интимных отношений;

2. налаживание между партнерами отношений, включающих больше доверия, понимания, поддержки, принятия.

В данном случае терапия является стратегией для лечения сексуальных дисфункций при отсутствии медицинской этиологии, то есть функциональных, или в качестве дополнения к медикаментозному лечению. Общий психологический подход - научить Клиента испытывать чувственность, радость, удовольствие от реального сексуального взаимодействия. Поэтому психолог или сексолог помогает осознать, какие именно запреты и тревоги (эмоциональные, поведенческие, когнитивные, межличностные, микросоциальные) мешают Клиенту находить удовольствия в реальном сексе. Несмотря на высокую эффективность терапии, не все случаи сексуальных нарушений, которые лежат в основе зависимости от виртуального секса, могут быть охвачены и излечены. Но более детальная аналитика выходит за рамки рассматриваемой тематики. Так или иначе, существует несколько основных подходов, которые стоит рассмотреть более подробно.

\section{Психоаналитическая терапия}

Психоаналитический подход предполагает раскрытие ранних причин сексуальных расстройств и их проработку с последующей дисквалификацией. В ходе длительного курса психоанализа с Клиентом проводятся постоянные, регулярные и активные занятия. Но здесь необходимо отметить ограниченное применение к решению практических сексуальных проблем человека, вследствие длительного курса лечения. Но, если нет необходимости быстрого достижения результатов, то этот подход часто применяется.

В соответствии с позицией Зигмунда Фрейда о сексуальных отклонениях, виртуальный секс, где партнер ищет партнера, можно отнести к первой группе - отклонения в отношении сексуального объекта [11]. Но если говорить о разрядке сексуального влечения, как об основной цели, то получается, что виртуальный секс имеет отклонения от сексуальной цели, поскольку ограничивается мастурбацией. А Фрейд считал, что совокуплени- 
ем называется акт непосредственно соединения гениталий. То есть у партнеров нет привычного полового акта, есть замена мастурбацией.

Форму виртуального секса с видеосвязью можно назвать более «открытой», поскольку есть возможность видеть партнера, степень его сексуального возбуждения. Здесь подмешиваются такие ощущения, как подглядывание, ощущение того, что смотреть можно, а трогать руками нельзя - такой способ виртуального секса похож на вуаеризм с одной стороны и эксгибиционизм с другой. «Виртуальный секс вытесняет нормальную сексуальную цель, оставляя, как писал Фрейд, возможность «показать свои гениталии для того, чтобы в награду получить возможность увидеть гениталии других» [12]. Мы можем сказать, что цель такого виртуального секса, это разглядывание и показывания себя.» Но, на самом деле, именно наблюдение и сексуальное возбуждение выплескиваются в оргазм. Во время виртуального секса с видеосвязью партнеры стимулируют свои эрогенные зоны, что приближает их к акту мастурбации.

В случае виртуального секса без визуального ряда, эти ограничения позволяют достраивать сексуальный образ, действия, половой акт в воображении партнеров. Эрогенная зона тоже переносится в область воображаемого. Это удовольствие в чистом виде, без переноса на партнера и всего остального в реальный мир. «Сексуальный партнер по другую сторону монитора всегда будет идеальным, помогающим перевести иллюзию в возбуждение и разрядку. Эту форму виртуального секса, можно назвать секс со своей психической реальностью. Несмотря на присутствие сексуального партнера, важным остается не он, а сам процесс фантазирования, то есть сексуальная цель, это «придумывание» самой сцены коитуса» [12].

В обоих случаях занятия виртуальным сексом мы видим человека, который, по сути, занимается мастурбацией. Таким образом, при высокой насыщенности в психическом пространстве, секс в реальности обедняется. Эти две формы, преследуют разные цели (разглядывание и показывание; фантазирование о коитусе), что, по мнению Фрейда, является перверсией и характерно для инфантильной сексуальности. При этом способе разрядки предварительное наслаждение становиться основным и делает невозможным наступление большего наслаждения - уже от удовлетворения. Подготовительный акт занимает место сексуальной цели. Уже эти наблюдения приводят нас к мысли об определенной степени невротичности Клиента. Тем не менее, психоаналитический подход призывает нас не считать перверсии отклонением, и виртуальный секс, как таковой. Отклонением считается полное замещение сексуальной жизни: когда никакой иной формы разрядки сексуального возбуждения, чем через виртуальный секс, нет.

\section{Семейная терапия}

Данный подход является весьма успешным, если мы рассматриваем зависимость от виртуального секса в контексте семейно-сексуальной дисгармонии. Супружеское расстройство представляет собой несоответствие между текущим воспроизведением ранее приобретенных навыков и идеальной моделью «здоровых» и «функциональных» супружеских отношений. Клинически расстройства проявляются в виде конфликта из-за разногласий (1) или как недостаток комплементарности (2).

1. В основе конфликта из-за разногласий лежит заблуждение, что стремление к определенному образу жизни исключает возможность существования альтернативного. Каждая из сторон старается привносить свои ценности и цели в отношения. Проявлениями являются: нарушение эмпатии и общности, деструктивные и безосновательные споры, расстройство коммуникации, отсутствие способов восстановить равновесие, прогрессирующее отдаление партнеров. Разрешение такого конфликта лежит только в способах его преодоления (а не в природе), то есть только при совместных усилиях на межличностном и внутреннем уровнях.

2. Снижение качества комплементарности обусловлено несостоятельностью паттернов, что проявляется нарастающей ригидностью отдельных элементов общения. Они становятся автоматическими, бесполезными, пустыми, что не отвечает совместным задачам семейной жизни.

В книге известных отечественных сексологов «Супружеская секс-терапия» [7] в рамках семейной терапии предлагается использовать известный подход к диагностике семейно-сексуальной дисгармонии Натана Акермана. Он выделяет три уровня диагностики: описательный, динамический, генетический. Первые два характеризуют качество семейной адаптации как «здоровых» и «нездоровых» тенденций и особенностей. Описательный предполагает классифицирование расстройств супружеского партнерства в границах симптомных кластеров, отражающих девиантные паттерны взаимодействия, в том числе, сексуальную неудовлетворенность. Динамический выявляет основные конфликты, способы их преодоления, паттерны комплементарности или отсутствие таковых, искажение функций взаимодействия, реализм, зрелость, стабильность и потенциал роста этих отношений. Генетический же осмысливает динамику эволюции отношений на протяжении добрачных и брачных отношений.

Психотерапевтическое консультирование выявляет реальное содержание конфликта и подводит супругов к обоюдному пониманию сути проблемы. Необходимо стимулировать эмпатию и коммуникацию, которая будет способствовать осмысленному, честному и оживленно- 
му обмену эмоциями, что, в конечном итоге, приведет к спонтанной и искренней духовной общности. По мере того, как супруги начинают «разворачивать» своё общение на психотерапевтических сессиях, они несомненно становятся ближе друг другу.

\section{Поведенческая терапия}

В данной концепции отдельные симптомы, вне зависимости от их природы и связи с какой бы ни было болезнью, рассматриваются как неправильное поведение, которое необходимо исправить специальными побуждающими приемами. Для лечения эмоциональных и сексуальных проблем Клиента используются методы оперантного обусловливания и разобусловливания. Терапия построена на подкреплении того спонтанного поведения, которое расценивается как желательное. При этом подкрепляется и случайное поведение, нужное нам - инструментальное научение, так и при осознании поисковой творческой активности - творческое научение. Кроме этого, некоторые специалисты используют также систематическую десенсибилизацию, аверсивное обусловливание и тренировку навыков. Например, нежелательное сексуальное поведение, такое как занятие мастурбацией при проигрывании в уме эпизодов ранее имевшего место эксгибиционизма, неоднократно сопровождается аверсивным стимулом. Это может быть, к примеру, болезненный, но безопасный для здоровья удар током, или вызывающий тошноту препарат, или очень неприятный запах. Точно так же аверсивный стимул может предъявляться человеку во время просмотра им фотографий или цветных слайдов, изображающих парафилическое поведение [1].

Сексуальная дисфункция в рамках поведенческой концепции рассматривается как обученное дезадаптивное поведение, по принципу фобии. Таким образом, можно предположить, что Клиент боится сексуального взаимодействия. Используя различные метода, специалист создаёт в сознании иерархию этих тревожных ситуаций - от менее угрожающих до более угрожающих. Например, легкая тревога может соответствовать ситуации перед поцелуем, а сильная о представлении секса, где пенис проникает во влагалище. Также можно научить Клиента справляться с тревогой через стандартную программу систематической десенсибилизации (или десенситизации), при которой тормозятся реакции, присущие обученной тревожности, путем выработки поведения, прямо противоположного тревоге. Вначале Клиент учится справляться с ситуациями, где тревога менее выражена, и постепенно переходят к более сложным моментам. При этом подход необязательно может быть чисто психотерапевтическим, сюда можно добавить гипноз, аутогенную тренировку, специальные упражнения для расслабления, лекарственные препараты.

Приобретение уверенности в себе позволяет Клиен- ту открыто и без страха выражать, осуществлять свои сексуальные потребности. По мнению сексологов, именно эти упражнения в сочетании с секс-терапией дают максимальный эффект: Клиент последовательно обучается выдвигать свои сексуальные требования и одновременно отвергать выполнение тех, которые считает некомфортными для себя [7]. Разумеется, участие основного партнера для Клиента повышает ценность предлагаемой терапии.

В настоящее время, существует множество психотерапевтических направлений, которые можно было применить в работе по зависимости от виртуального секса. К уже выше рассмотренным необходимо добавить следующие: бихевиоральный подход, телесно-ориентированная терапия, когнитивная терапия, нарративная терапия, трансакционный анализ, позитивная психотерапия, использование восточных методик, гипнотерапия, групповая секс-терапия, секс-терапия с суррогатным партнером.

Таким образом, практически все сексуальные проблемы, с которыми сталкиваются сексологи, лежат отнюдь не в области «ниже пояса», а на практике являются следствием сочетания физических, психических, психологических факторов, которые требуют комплексной многокомпонентной терапии. Поэтому, сталкиваясь и работая с подобными случаями, целесообразно применять весь спектр психотерапевтического инструментария - применять все удачные методики и наблюдения независимо от академической направленности; другими словами, применять интегративный подход в работе над стратегией и тактикой консультирования.

\section{ЗАКАЮЧЕНИЕ}

Виртуализация сексуальной культуры наравне с отчуждением секса от эмоциональной составляющей межличностного взаимодействия являются характеристиками неограниченного сексуального поведения как феномена современного общества [10]. Тем не менее, психологическую зависимость от виртуального секса скорее следует рассматривать, как один из вариантов невротического расстройства, возникшего вследствие интенсивного технологического развития. Человеком овладевает навязчивое стремление совершать один и тот же ритуал, что в итоге превращается в самоцель. Тогда уже сам процесс приносит какое-то временное удовлетворение, которое никак не может быть насыщено. При этом страдают другие стороны жизни: социальная жизнь, профессиональная, семейная, интимная. Потихоньку виртуальный секс со своим насыщенным эмоциональным пространством вытесняет секс реальный и, по сути, прерывает социальные контакты с окружением.

Сам по себе виртуальный секс, как неотягощенное явление, может иметь и достоинства, и недостатки. По- 
мимо уже описанных ранее в работе таких аспектов, как лучшая форма удовлетворения эротических фантазий; познавательные возможности; стимулирование сексуальной активности; компенсация недостающих реальных отношений и т.д., есть ещё аспект, когда мы рассматриваем виртуальный секс, как терапию для нейтрализации отклоняющихся от нормы сексуальных интересов. Например, когда психолог или сексолог назначают пациенту проводить какое-то время в чатах с подобным контентом (данные на основе супервизорской консультации). К недостаткам относятся: обесценивание интимных эротических отношений; разжигание половых инстинктов, приводящих к насилию; провоцирование сексуальных расстройств; замещение реального секса и разрыв отношений с постоянными партнерами и т.д. Получается, что наверняка нельзя оценить пользу или вред от занятий виртуальным сексом. Всё зависит от конкретного человека, стадии его психосексуального развития, его семейной интимной ситуации, его социальных трудностей и физиологических особенностей. Сами по себе сексуальные расстройства часто приводят к развитию ситуативных психических расстройств невротического или депрессивного плана, которые возникают точно так же, как в ответ на любое другое стрессовое воздействие [7].

Один из известных специалистов в области сексологии И.С. Кон считает, что виртуальный секс сам по себе не страшен, а скорее расширяет границы сексуального опыта. В отличие от физической измены, виртуальный секс не рассматривается как нарушение партнерских обязательств. Но если объем виртуального секса чрезмерен, и партнеры скрывают этот опыт друг от друга, это неизбежно подрывает их связь, поскольку честность лежит в основе партнерских отношений [9]. Поэтому всё же удовлетворение или недовольство в паре обоих партнеров является лучшим критерием оценки сексуального поведения и дисфункции.

Каждый сексолог знает, что поводом для разрушения партнерских отношений могут быть и ещё более «ничтожные» (по сравнению с зависимостью от виртуального секса) отклонения от субъективных представлений о «правильном» интимном поведении (данные на основе супервизорской консультации). Четкое понимание непосредственно индивидуальности представлений и восприятие происходящего является показателем того, что они относятся к структуре личности и носят поведенческий, социальный характер. Для исследований этих конкретных событий в жизни клиентов в нашем распоряжении имеется огромный выбор психотерапевтического инструментария: психоаналитическая терапия, семейная терапия, поведенческая и многие другие. В каждом из подходов есть свои плюсы и минусы, многое также зависит от клиента - целесообразно выбирать именно комплексный интегративный подход, который наилучшим образом будет отвечать рассмотренному запросу.

\section{ЛИТЕРАТУРА}

1. Аверсивное обусловливание. Определение. Психологос: Энциклопедия практической психологии http://www.psychologos.ru/articles/view/aversivnoe_ obuslovlivanie

2. Васильченко Г.С. Материал Википедии https://ru.wikipedia.org/wiki/Сексуальное_поведение_человека\#сіte_note-14

3. Виртуальный секс. Определение. Материал Википедии https://ru.wikipedia.org/wiki/Виртуальный_секс

4. Йоффе Е.В. Сексуальная культура и трансгрессия сексуальности: анализ конфликта // Гендерные разночтения: Материалы IV межвузовской конференции молодых исследователей «Гендерные отношения в современном обществе: глобальное и локальное» (22-23 октября 2004 г.) / 0тв. ред. М.В. Рабжаева. - СПб.: Алетейя, 2005. - 384 с. С.160-168

5. Йоффе Е.В. Эксплуатация образов сексуальности в СМИ, рекламе и PR-технологиях // Вариации на тему Гендера: Материалы межвузовской конференции молодых исследователей «Гендерные отношения в российском обществе: история и современность»/ Отв. ред. Т.А. Мелешко, М.В. Рабжаева. - СПб.: Алетейя, 2004. - 316 с. С. 127-137

6. Кащенко Е.А. Секс: реальный и виртуальный. Изд. стереотип. - М.: Едиториал УРСС, 2014. - 192 стр.

7. Кибрик Н.Д., Прокопенко Ю.П. Супружеская секс-терапия. - Москва: Книгоизд. «АБВ», 2015. - 224 стр.

8. Кириллов В. Виртуальный секс. Зависимость. 2012 http://www.medpulse.ru/health/prophylaxis/psychotherapy/12488.html

9. Кон И.С. Сексология. Учебное пособие. - М., Изд.центр «Академия», 2004. - 384 стр.

10. Конина М.А., Холмогорова А.Б., Сорокова М.Г. Феномен неограниченного сексуального поведения в современном обществе: патологические тенденции культуры или патология личности? // Консультативная психология и психотерапия. 2014. Том 22. № 2. С. 88-118.

11. Фрейд 3. Очерки по психологии сексуальности. - М., Эксмо-пресс, 2017. - 352 стр.

12. Штырбу Е.Е. Виртуальный секс, психоаналитический взгляд 2009 http://psyfactor.org/lib/virtual-sex.htm

с Макарова Мария Владимировна (maria.makarova.mow@gmail.com).

Журнал «Современная наука: актуальные проблемы теории и практики» 